\title{
SENTENCIA SOBRE INTERPRETACIÓN DEL ART. 54 LBPA QUE ESTABLECE LA INTERRUPCIÓN DE LOS PLAZOS JUDICIALES MIENTRAS SE RESUELVEN RECURSOS ADMINISTRATIVOS INTERPUESTOS PREVIAMENTE (CORTE SUPREMA)
}

\section{Comentario de Juan Carlos Ferrada Bórquez}

Santiago, treinta y uno de mayo de dos mil seis.

VISTOS: Se reproduce la sentencia en alzada con excepción de los considerandos $4^{\circ}$ a $15^{\circ}$, inclusive, que se eliminan. En el fundamento primero se excluye su párrafo tercero. En el motivo segundo se omite la expresión los actos administrativos ya referidos y que se resumen en. Y se tiene además presente:

$1^{\circ}$ Que, como ha quedado demostrado en estos antecedentes, el Sr. Superintendente de Casinos de Juego por oficio ordinario N 121 de 1 de septiembre de 2005 tuvo por no presentada la solicitud de la recurrente para el permiso de operación de un casino de juegos, por no cumplir ésta con lo previsto en la letra c) del artículo 17 de la Ley $\mathrm{N}^{\circ}$ 19.995. En contra de esta decisión administrativa, dicha sociedad afectada la impugnó por la vía del recurso extraordinario de revisión que contempla el artículo 60 de la Ley de Bases de los Procedimientos Administrativos, arbitrio que fue rechazado, por la misma autoridad recurrida, por resolución exenta $\mathrm{N}^{\circ} 124$ de 12 de diciembre de 2.005;

$2^{\circ}$ Que también es un hecho no discutido que respecto de la resolución $\mathrm{N}^{\circ} 121$, la recurrente tomó conocimiento de ella a lo menos el día que dedujo la aludida revisión administrativa, situación que aconteció el día 2 de septiembre del 2005. Es también un hecho demostrado que la acción de protección se dedujo el día 23 de diciembre del 2005;

$3^{\circ}$ Que no se puede discutir en este juicio de protección, que la resolución que tuvo por no presentada la solicitud de permiso para la operación de un casino de juego, fue dictada dentro de un procedimiento administrativo regulado por la Ley 19.995, que permite la autorización, funcionamiento, administración y fiscalización de este tipo de actividades. Consecuente con lo anterior y, frente a los objetivos ya dichos, resulta evidente también la aplicación de la Ley 19.880 que establece y regula la base del procedimiento administrativo de los Actos de la Administración del Estado. Conforme a esta última normativa, este proceso, como lo señala el artículo 18, constituye una sucesión de actos trámite vinculados entre sí, que tiene por finalidad producir un acto administrativo terminal, siguiendo 
el desarrollo que este precepto estatuye, el que se agotará, sin lugar a dudas, una vez desestimados los recursos de reposición y jerárquico a que se refiere el artículo 59 del aludido texto legal, y sin perjuicio además del recurso extraordinario de revisión que puede deducir un agraviado o de la revisión de oficio de la administración, según se explica en los artículos 60 y 61 del mismo estatuto;

$4^{\circ}$ Que el artículo 54 de la aludida ley 19.880 preceptúa que, interpuesta una reclamación ante la Administración, no podrá el mismo reclamante deducir igual pretensión ante los Tribunales de Justicia, mientras aquella no haya sido resuelta o transcurrido el plazo para que deba entenderse desestimada. Se agrega por la norma, que planteada la reclamación se interrumpirá el plazo para ejercer la acción jurisdiccional. Este término volverá a contarse desde la fecha en que se notifique el acto que la resuelve o, en su caso, desde que la reclamación se entienda desestimada por el transcurso del plazo. Y finaliza este precepto: si respecto de un acto administrativo se deduce acción jurisdiccional por el interesado, la administración deberá inhibirse de conocer de cualquier reclamación que éste interponga sobre la misma pretensión;

$5^{\circ}$ Que la sentencia apelada, sobre la base del artículo antes citado, declaró que la interposición del recurso extraordinario de revisión ha provocado dos efectos con relación a la acción de protección que consagra el artículo 20 de la Carta Fundamental. En primer lugar, impide al afectado deducir este último arbitrio y, en seguida, que ha quedado interrumpido el plazo para interponerlo, por constituir la protección una acción jurisdiccional de aquellas a que se refiere el expresado artículo 54;

$6^{\circ}$ Que sin perjuicio que sea dudosa la interpretación antes aludida, en lo que respecta al recurso extraordinario de revisión, que contempla el artículo 60 de la ley 19.880, puesto que esta impugnación administrativa sólo procede contra actos administrativos firmes, o sea, cuando el procedimiento respectivo adquiere el efecto terminal a que se refiere el artículo 18 de la misma ley y en consecuencia, debe admitirse, dentro de una regularidad procedimental, que se hayan agotado los recursos ordinarios de reposición y jerárquico, naturaleza que en caso alguno tenía la resolución 121, es lo cierto que la norma del artículo 54 aludida se encuentra en completa contradicción con el artículo 20 de la Constitución Política de la República;

$7^{\circ}$ Que, en efecto, este último artículo estableció la acción constitucional de protección, que permite a cualquiera persona acudir a determinada jurisdicción, cuando por causa de actos u omisiones arbitrarios o ilegales sufra privación, perturbación o amenaza en el legítimo ejercicio de ciertos y precisos derechos y garantías, para que la Corte de Apelaciones respectiva adopte de inmediato las providencias que juzgue necesarias, para restablecer la juridicidad quebrantada y asegurar la debida protección del afectado, sin perjuicio de los demás derechos que pueda hacer valer ante la autoridad o los tribunales correspondientes;

$8^{\circ}$ Que conforme al texto constitucional este denominado recurso de protección se ha establecido como un estatuto jurídico sustantivo y procesal cuyo fin es amparar de 
manera eficaz, pero en procedimiento breve y sumario, determinadas garantías de rango mayor y de especial respeto, frente a actos u omisiones ilegales o arbitrarios, que afecten el legítimo ejercicio de tales derechos esenciales. En su discusión, las actas respectivas dejan testimonio del objetivo de este mecanismo de protección: don Enrique Ortúzar expresaba: Es un procedimiento de emergencia, por decirlo así, que tiene por objeto lisa y llanamente, mientras se discute ante la justicia ordinaria en forma lata el problema planteado, restablecer el imperio del derecho que ha sido afectado; don Enrique Evans, a su vez, señalaba en torno de esta acción, que éste es un instrumento: similar al del amparo respecto de otras determinadas garantías constitucionales, de libertades y derechos que están en la Carta Fundamental, que permite la solución rápida, eficaz, de un atropello que se está produciendo y que afecta el ejercicio de una de esas libertades, garantías y derechos constitucionales. (Sesión 214 Actas Oficiales de la Comisión Constituyente);

$9^{\circ}$ Que por consiguiente, frente a la afectación del legítimo ejercicio de un derecho o garantía, expresamente protegido por el artículo 20 de la Constitución, se alza como contrapeso a dicho gravamen esta acción cuyo objetivo básico es, a través de providencias cautelares urgentes, restablecer el imperio del derecho. Es obvio que el ejercicio de esta facultad es jurisdiccional, pero por su relevancia se le exige a los tribunales, además, el ejercicio legítimo de sus facultades conservadoras cuyo sentido histórico y jurídico fue precisamente entregarle a este Poder del Estado, como función conexa relevante, la de asegurar el respeto de las garantías y derechos que la Carta Fundamental contempla en favor de las personas;

$10^{\circ}$ Que de lo razonado emerge como una consecuencia básica que el amparo que asegura la acción constitucional deducida, no es condicional, ni accesorio, no puede interrumpirse, ni suspenderse en modo alguno, puesto que el texto del precepto busca como objetivo básico el poner pronto remedio, frente a los efectos que puede ocasionar, a un derecho relevante y esencial de toda persona, un acto que prima facie, puede reputarse como arbitrario o ilegal y que prive, perturbe o amenace el legítimo ejercicio de tal derecho. Y desde esta perspectiva, el constituyente completó la idea, estableciendo en la parte final del inciso primero, que el ejercicio irrestricto de la acción de protección lo era sin perjuicio de los demás derechos que pueda hacer valer el afectado, ante la autoridad o los tribunales correspondientes;

$11^{\circ}$ Que, profundizando la idea, es útil consignar el sentido que en esta parte de la norma se expresó por el constituyente y de que dan fe las actas oficiales de la Comisión y en particular la de la sesión 216. En dicha audiencia se explica el sentido de la redacción. Se pregunta el comisionado señor Evans que esta última frase es absolutamente innecesaria la expresión pues no tiene objeto, ya que no se ve porqué se va a suponer que la existencia de estos recursos extinguirán otro tipo de acciones o derechos que puede tener el afectado con ocasión o a causa del acto u omisión arbitraria o ilegal de que ha sido víctima. Le responde el Ministro de Justicia Señor Schweitezer que, no obstante lo dispuesto en el artículo 16 de la Constitución, la ley dijo otra cosa, recordando que el artículo 306 del Código de Procedimiento Penal señaló que el amparo no procedía si se habían interpuesto otros recursos legales y estima útil el agregado sin perjuicio 
de las acciones que procedan, porque en tal caso sería la propia Constitución la que estaría salvando el eventual problema. Acotó el Señor Silva Bascuñán, concordando con el Ministro, en que se quiere que precisamente no haya obstáculos para que este recurso (el de protección) sea efectivo, cualesquiera que sean los demás caminos que se adopten dentro del ordenamiento jurídico y, en ese sentido, se acordó incluir la expresión sin perjuicio de los demás derechos que pueda hacer valer ante la autoridad o los tribunales, coincidiéndose en que la expresión derechos incluía el derecho de petición, las acciones, gestiones, etcétera. El autor Eduardo Soto Kloss en su obra El Recurso de Protección, precisando esta parte del precepto y concordando con algunas sentencias, que comenta sobre la materia, apunta a que el sentido del recurso de protección es proporcionar al ciudadano una tutela expedita de sus derechos fundamentales, ágil, pronta y eficaz; compatible con todas las demás previsiones normativas del ordenamiento jurídico tendientes a asegurar jurisdiccionalmente sus derechos, y dejando al propio agraviado la libre elección del remedio procesal que estime más apto y adecuado en un determinado momento para la defensa o protección de su esfera subjetiva por el Derecho y violada ilegal o arbitrariamente por un tercero;

$12^{\circ}$ Que de lo que se lleva dicho emerge como una cuestión indubitada que el recurso de protección resulta totalmente compatible con el ejercicio de cualquier otra acción jurisdiccional y administrativa dirigidas a enervar los efectos nocivos de un acto ilegal o arbitrario, compatibilidad que por su establecimiento de carácter constitucional prevalece respecto de cualquier intento legislativo que pretenda coartar el ejercicio de esta acción suprema, porque precisamente ese fue el espíritu del constituyente nítidamente manifestado en la discusión sobre el tema. En este sentido, sostener que una simple ley pueda impedir, interrumpir o suspender el derecho de esta acción, sería precisamente darle la razón al temor manifestado por los comisionados redactores del precepto en estudio, en cuanto a que por la vía de una norma de rango inferior a la Constitución se colocara límites al ejercicio legítimo que le asiste a toda persona de recabar de protección cualquier acto u omisión ilegal o arbitrario que afecte garantías fundamentales;

$13^{\circ}$ Que en este sentido, en caso alguno, puede considerarse que la interposición de que habla el artículo 54 de la acción jurisdiccional, esté referida al recurso de protección porque precisamente el artículo 20 de la Carta Fundamental se anticipó a declarar que esta acción es sin perjuicio de otros derechos e implícitamente prohibió a la ley, norma de rango inferior, colocar cortapisas al pleno ejercicio de este arbitrio. En estas condiciones el artículo 54 aludido no impidió de ninguna manera, que los afectados por la resolución 121 recurrida pudieran impetrar la protección constitucional;

$14^{\circ}$ Que en consecuencia, como el conflicto normativo se ha producido entre el artículo 54 de la Ley $\mathrm{N}^{\circ} 19.880$ y el sentido y alcance del artículo 20 de la Constitución Política de la República, este debate no afecta a las normas que se contienen en el Auto Acordado sobre Tramitación y Fallo del Recurso de Protección, dictado por esta Corte, conforme a una disposición de rango constitucional (Acta Constitucional $\mathrm{N}^{\circ} 3$ de 1.976) y en concordancia con sus facultades económicas. 
En este sentido, parece claro que el acto ilegal o arbitrario tiene como única causa la resolución $\mathrm{N}^{\circ} 121$ de 1 de septiembre de 2.005, puesto que el resultado de una impugnación administrativa -recurso extraordinario de revisión- importa sólo un reexamen en esa sede del acto cuestionado y, por consiguiente, la resolución No 124 del 12 de diciembre de 2.005 que desestimó ese recurso extraordinario no ha podido otorgar un nuevo plazo para el ejercicio de la acción de protección;

$15^{\circ}$ Que de lo expuesto en los motivos anteriores resulta meridianamente claro que la acción de protección ha sido interpuesta fuera del plazo fatal que señala el $\mathrm{N}^{\circ} 1$ del Auto Acordado de esta Corte Suprema sobre la materia.

Por estas consideraciones y visto lo dispuesto en el Auto Acordado antes referido y el artículo 20 de la Constitución Política de la República, SE REVOCA la sentencia apelada de cinco de abril último, escrita a fojas 174 , y se declara inadmisible por extemporáneo, el recurso de protección deducido a fojas 1.

Acordada con el voto en contra del Abogado Integrante Sr. José Fernández Richard, quien fue de parecer de confirmar en todas sus partes la sentencia en alzada, con el mérito de sus propios fundamentos y teniendo, además, presente las siguientes consideraciones:

Primero: Que la existencia del Auto Acordado de la Excma. Corte Suprema sobre tramitación y fallo de los recursos de protección, no impide a juicio del disidente, que los afectados por una resolución administrativa, supuestamente arbitraria o ilegal hagan uso de los recursos que les franquea la Ley $\mathrm{N}^{\circ} 19.880$ sobre Bases de los Procedimientos Administrativos que rigen los actos de los Órganos de la Administración del Estado;

Segundo: Que el mencionado cuerpo legal en su Capítulo IV sobre Revisión de los actos administrativos, dispone en el Párrafo $1^{\circ}$ sobre Principios generales, en su artículo 54 que Planteada la reclamación se interrumpirá el plazo para ejercer la acción jurisdiccional, de modo que si ese recurso es interpuesto dentro del plazo pendiente para deducir la acción cautelar que establece el artículo 20 de la Carta Fundamental, debe concluirse que el plazo para intentar a posteriori el recurso de protección ha quedado suspendido;

Tercero: Que a juicio de este disidente el recurso que franquea el constituyente en el artículo 20 de la Constitución Política de la República se encuentra comprendido dentro del concepto de acción jurisdiccional a que se refiere el artículo 54 de la Ley $\mathrm{N}^{\mathrm{o}} 19.880$ sobre Bases de los Procedimientos Administrativos que rigen los actos de los Órganos de la Administración del Estado.

Regístrese y devuélvase con sus agregados. Redacción a cargo del Ministro Sr. Juica y del voto disidente su autor. $\mathrm{N}^{\mathrm{o}} 1717-2006 .-$

Pronunciado por la Tercera Sala, integrada por los Ministros Sr. Ricardo Gálvez, Sr. Milton Juica, Srta. María Antonia Morales y Sr. Adalis Oyarzún; y el Abogado Integrante Sr. José Fernández. Autorizado por la Secretaria Subrogante Sra. Carola A. Herrera Br. 


\section{Comentario}

Empieza a ser habitual en nuestro derecho encontrarse con sentencias judiciales que, amparadas en las buenas intenciones de los jueces, terminan siendo construcciones jurídicas no muy prolijas y que pugnan con principios elementales de la disciplina jurídica. Precisamente la sentencia transcrita es un buen ejemplo de ello, ya que a partir de un encomiable propósito no confesado de ampliar la tutela de derechos fundamentales por intermedio del Recurso de Protección, termina inhibiendo su aplicación en muchos otros casos.

En este caso, el punto central de la discusión es determinar la extemporaneidad o no del Recurso de Protección interpuesto por la empresa "Thunderbird IEG”, frente a la resolución administrativa dictada en un recurso extraordinario de revisión administrativa. En otras palabras, se trata de determinar si el plazo de 15 días dispuesto en el autoacordado que regula la tramitación del Recurso de Protección, se cuenta desde la fecha en que se dicta el original o desde que se rechazó el recurso de revisión interpuesto.

Es evidente, y así lo sostiene acertadamente la Excma. Corte Suprema (considerando $14^{\circ}$ ), que el recurso extraordinario de revisión administrativa no puede hacer revivir los plazos de caducidad previstos en el ordenamiento jurídico. En esto la sentencia que rechaza el Recurso de Protección interpuesto en estos autos es del todo razonable. Sin embargo, ello no pugna con la norma de ordenación de las vías administrativas y judiciales de impugnación a que se refiere el Art. 54 de la Ley $\mathrm{N}^{\circ} 19.880$ de Bases de los Procedimientos Administrativos (en adelante LBPA), ni menos contradice, como así lo sugiere el sentenciador de forma tan excesiva (considerando $6^{\circ}$ ), el Art. 20 de la Constitución Política de la República (en adelante CPR). Así, los problemas de este fallo no son con la decisión, sino con los argumentos expuestos por la Corte para su adopción.

Lo explicaré del siguiente modo. El Art. 54 LBPA establece un orden de prelación del ejercicio de los mecanismos administrativos y jurisdiccionales de impugnación de los actos administrativos. Dicha ordenación no tiene un carácter estricto, sino que entrega a los afectados por la resolución administrativa elegir el procedimiento de impugnación, admitiendo la vía administrativa siempre como mecanismo que opera prima facie del conocimiento judicial del conflicto.

En esto nuestro legislador fue más innovador y garantista que otros ordenamientos administrativos, ${ }^{1}$ ya que no exigió el agotamiento de la vía administrativa como requisito de admisibilidad de la impugnación judicial, lo que ha sido tradicionalmente criticado por la doctrina administrativa como una limitación innecesaria del derecho fundamental de acceso a los tribunales de justicia. ${ }^{2}$ Así, nuestra LBPA flexibilizó el

${ }^{1}$ En el derecho español, por ejemplo, la admisibilidad del recurso contencioso-administrativo queda sujeto al agotamiento de las vías administrativas de impugnación, requisito indispensable para la procedencia de la demanda ante el tribunal (Art. 25.1 y 69 de la Ley 29/1998 de la Jurisdicción ContenciosoAdministrativa). En este sentido, ver González Pérez, J. Manual de Derecho Procesal Administrativo, Civitas, Madrid, 2001, pp. 242-243.

${ }^{2}$ Por todos, Fernández Torres, J. Jurisdicción administrativa revisora y tutela judicial efectiva, Civitas, Madrid, 1998, pp. 54 y ss. 
sistema de impugnación de los actos administrativos, modificando también la regla de impugnación administrativa previa que opera en una serie de procedimientos especiales previstos en nuestro propio ordenamiento. ${ }^{3}$

Ahora bien, para que este sistema funcione, es preciso establecer un mecanismo de coordinación de ambos procedimientos, ya que de lo contrario, evidentemente, la opción se vuelve inoperante y obliga al afectado utilizar ambos caminos de impugnación previstos en el ordenamiento. Así, se estableció que "planteada la reclamación (administrativa) se interrumpirá el plazo para ejercer la acción jurisdiccional”, plazo que sólo empezará a correr a contar del rechazo del reclamo o cuando éste se considere desestimado (silencio administrativo negativo). En este contexto, los afectados pueden, si es que así lo estiman adecuado, utilizar la vía de impugnación administrativa de la decisión administrativa como primer camino de reclamo, dejando la vía judicial como último recurso de control de legalidad del acto, la que estará abierta y disponible una vez cerrada la fase administrativa o inicialmente, si es que optaran directamente por esta vía.

Llegado a este punto, la cuestión entonces se plantea en torno a como opera el Recurso de Protección como mecanismo de impugnación de los actos administrativos. Siguiendo la doctrina tradicional, ${ }^{4}$ este recurso constituye el procedimiento ordinario de impugnación de los actos administrativos ilegales o arbitrarios, operando en todo clase de conflictos en los que se envuelve una acción u omisión administrativa. ${ }^{5}$ Desde este punto de vista, no hay duda que la procedencia del Recurso de Protección para la impugnación de los actos administrativos debe sujetarse a las reglas generales de prelación dispuestas en el Art. 54 LBPA, ya que no tendría ninguna entidad diversa de las acciones judiciales ordinarias de impugnación en este ámbito.

No obstante, en una perspectiva algo más compleja, el Recurso de Protección no es un contencioso administrativo ordinario, sino es un procedimiento calificado de amparo de derechos fundamentales, que no controla la legalidad de los actos administrativos, sino tutela ciertos derechos constitucionales de las personas. ${ }^{6}$ En este contexto, su procedencia no está condicionada a la interposición previa de reclamación administrativa

\footnotetext{
${ }^{3}$ Así ocurre por ejemplo con los Reclamos de ilegalidad municipal (Art. 140 de la Ley Orgánica Constitucional de Municipalidades), los Reclamo de ilegalidad regional (Art. 102 de la Ley Orgánica Constitucional de Gobierno y Administración Regional o los reclamos de ilegalidad por actuaciones del Banco Central de Chile (Art. 69 de la Ley Orgánica Constitucional del Banco), por nombrar sólo algunos casos.

${ }^{4}$ Ver, Soto Kloss, E. “Amparo Judicial y Recurso de Protección”, Revista de Derecho Público Nos 19/20, 1976, pp. 156-158 y, del mismo autor, "El Recurso de Protección y el amparo de los derechos de las personas frente a las arbitrariedades de la Administración del Estado”, Revista de Derecho, Universidad Central, año V, enero-junio 1991, pp. 198-199.

${ }^{5}$ De alguna manera esta afirmación está detrás del establecimiento del Recurso de Protección como mecanismo ordinario de impugnación de las actuaciones del Consejo Superior de Educación previsto en el proyecto de Ley que establece un sistema nacional de aseguramiento de la calidad de educación superior (Art. 42), en el que se asegura la procedencia de este Recurso, sin condicionar éste a la tutela de derecho fundamental alguno.

${ }^{6}$ En este sentido, puede consultarse mi trabajo "El Recurso de Protección como mecanismo de control contencioso administrativo”, en Justicia Administrativa, J.C. Ferrada (coor.), Lexis Nexis, Santiago, 2005, pp. 129 y ss.
} 
o judicial alguna, aunque, evidentemente, su ejercicio sólo puede hacerse en el plazo de 15 días de dictado el acto administrativo que vulnera un derecho fundamental que se pretende amparar.

Esta última pareciera ser la posición sustentada por la Excma. Corte en el fallo en comento. Así, para nuestro más alto tribunal, el carácter de procedimiento de urgencia de tutela de derechos fundamentales que presenta el Recurso de Protección, haría inaplicable la regla de interrupción del plazo prevista en el Art. 54 LBPA.

Tal conclusión es evidentemente absurda. En primer lugar, porque la formulación de una regla como la señalada constituiría un grave perjuicio para los ciudadanos y una carga inaceptable para la tutela de sus derechos, ya que les obligaría a ejercer en cada caso los mecanismos ordinarios de impugnación administrativo y el Recurso de Protección en forma paralela, lo que implica un desgaste innecesario del aparato jurisdiccional y un esfuerzo desmedido para los administrados. De esta forma, el Recurso de Protección operaría como un mecanismo excepcional de tutela de derechos -lo que en sí mismo no es descartable-, pero inoperable para el control de los actos administrativos que vulneran derechos fundamentales.

De este modo, la sentencia en comento recoge las contradicciones del Recurso de Protección en nuestro medio, navegando entre ser un mecanismo de amparo de derechos fundamentales o un contencioso administrativo ordinario para controlar la actividad administrativa. Esta dicotomía la asume el fallo, pero no la resuelve acertadamente, haciendo evidente la confusión de conceptos. 